\title{
A Importância e o Uso de Ferramentas da Qualidade pelo Engenheiro Clínico Para o Sistema de Gestão de Acreditação Hospitalar
}

Title: The Importance and use of quality tools by the clinical engineer for the hospital accreditation management system

\author{
Marcos Alberto ${ }^{1}$ (D) http://orcid.org/0000-0003-1019-6230 \\ Walmir Pedrosa ${ }^{1}$ \\ ${ }^{1}$ Escola Politécnica de Pernambuco, Universidade de Pernambuco, Recife, Brasil, \\ E-mail do autor principal: Marcos Alberto alberto mafs@hotmail.com
}

\section{Resumo}

Em um mercado cada vez mais competitivo e dinâmico, a qualidade impacta diretamente na sobrevivência e no destaque de empresas e instituições, inclusive para a prospecção de clientes. Buscando destaque no mercado de prestação de serviços de saúde, a Acreditação Hospitalar se dá como um enorme diferencial frente aos concorrentes. A Acreditação Hospitalar é uma certificação semelhante a International Organization for Standardization (ISO), porém direcionada exclusivamente a organizações de prestação de serviços em saúde. Trata-se de um método de avaliação voluntário, periódico e reservado dos recursos institucionais dedicado a hospitais, clínicas ou laboratórios para garantir a qualidade de assistência por meio de padrões previamente definidos, em que é de vital importância a participação do setor de Engenharia Clínica, parte responsável pela gestão das tecnologias de equipamentos utilizados nestas instituições. Este trabalho aborda um estudo direcionado ao uso de Ferramentas de Gestão da Qualidade, como uso de indicadores e ciclo PDCA, nos processos de Acreditação Hospitalar, abordando e demonstrando como o seu uso, no setor de Engenharia Clínica, pode atender os requisitos dos órgãos de Acreditação Hospitalar.

Palavras-Chave: Acreditação Hospitalar; Engenharia Clínica; Ferramentas da Qualidade.

\section{Abstract}

In an increasingly competitive and dynamic market, quality has a directly impact the survival and prominence of companies and institutions, including customer prospecting. Seeking prominence in the provision of health services market, Hospital Accreditation is given as a great advantage against competitors, Hospital Accreditation is a huge differential compared of competitors. Hospital Accreditation is a certification similar to International Organization for Standardization (ISO), but directed exclusively to organizations providing health services. It is a method of voluntary, periodic and reserved evaluation of the institutional resources dedicated to hospitals, clinics or laboratories to guarantee the quality of care through predefined standarts. In which is of vital importance the participation of the Clinical Engineering sector, part responsible for the management of equipment technologies used in these institutions. This work addresses a study directed to the of Quality 


\title{
A Importância e o Uso de Ferramentas da Qualidade pelo Engenheiro Clínico Para o Sistema de Gestão de Acreditação Hospitalar
}

\begin{abstract}
Management Tools, such as the use of indicators and PDCA cycle, in the Accreditation process, addressing and demonstrating how its use in the Clinical Engineering sector can meet the requirements of the Hospital Accreditation.
\end{abstract}

Key-words: Hospital Accreditation; Clinical Engineering; Quality Tools.

\section{Introdução}

Este artigo demonstra a importância do setor de Engenharia Clínica para uma Organização Prestadora de Serviços de Saúde (OPSS) nos processos de gestão para acreditações hospitalares, bem como as vantagens e os benefícios trazidos com a utilização de Ferramentas Gerenciais da Qualidade por este setor durante esta ação. Com o foco principal voltado aos processos do selo de acreditação nacional, ofertado pela própria Organização Nacional de Acreditação (ONA), e ao selo internacional de acreditação da Joint Commission International (JCI), oferecido no Brasil pela Consórcio Brasileiro de Acreditação (CBA).

Pelo disposto acima, para a elaboração deste artigo, foi realizada uma revisão bibliográfica, tendo como base referencial: artigos, livros, anais, manuais de acreditação e demais publicações destinadas à acreditação hospitalar, uso de ferramentas da qualidade, qualidade na área de saúde e boas práticas de engenharia clínica em OPSS envolvidas em processos de acreditação, tanto nacionais quanto internacionais.

Este tema, tem como justificativa o grande avanço e variedade da tecnologia dos equipamentos relacionados à prevenção, ao diagnóstico, à reabilitação e ao tratamento da saúde dos pacientes, pela crescente procura das OPSS pelos selos de acreditação (em sua maioria por organizações privados da área de saúde) e pelo crescente aumento da disputa e destaque no mercado de saúde, bem como uma maior preocupação das instituições com a segurança dos pacientes relacionada ao uso de equipamentos médico-hospitalares, e a qualidade dos serviços prestados nesta área, e, ainda, à análise dos custos envolvidos com o gerenciamento dos equipamentos médico-hospitalares [1].

\subsection{Um breve histórico sobre a qualidade}

A noção de qualidade remonta até mesmo o aparecimento do grupo Homo sapiens, onde já havia uma seleção nos alimentos colhidos na natureza, evoluindo para a agricultura, e na escolha das lascas de pedras, que fariam parte de seus utensílios e armas de caça, onde também evoluíram com o uso do metal na fabricação destas. Naquele momento da história a qualidade não era explicita, porém já aparecia como um conceito intrínseco para aquela época [2].

Com o avançar dos tempos, o conceito de qualidade foi ganhando mais abrangência, mais preocupação formal, inclusive com a inserção de mercados ao redor do mundo. Nesse cenário, a concepção de qualidade do produto/serviço, era medida pela repercussão dentre os clientes que o produto/serviço possuía, era uma variável mais fácil de se mensurar, pois havia o contato direto do fabricante/prestador do produto/serviço com o cliente final. Neste contexto, pode-se citar os antigos artesões, que faziam todo o processo de produção de suas peças, desde a aquisição da matéria-prima até o pós-venda, verificando se o seu produto estava de acordo com as expectativas do cliente e podendo rever qualquer etapa de seu processo, caso não houvesse o retorno esperado [3].

Uma grande mudança veio com a Revolução Industrial, onde houve uma evolução no processo de avaliação da qualidade dos produtos/serviços oferecidos. Agora o que se buscava era obter uma uniformidade nos processos de fabricação. Foi nesse momento que o conceito de qualidade começou a ser empregado com mais força e distinção no mercado. Nesta ocasião houve a mudança na questão de verificação da qualidade, passando a se verificar mais o processo de manufatura do que o produto final, mostrando uma grande evolução nessa área [3]. 
Durante a Primeira Guerra Mundial, houve outro grande avanço da qualidade. Devido à enorme demanda de produção de material bélico seguro e de qualidade, para o uso na guerra, foi criada a figura do inspetor de qualidade no processo de fabricação, com certa imposição do governo para com os fabricantes destes materiais. Este profissional seria responsável pela verificação da qualidade dos produtos, em todas as suas etapas de produção [2].

Durante a Segunda Guerra Mundial houveram outros avanços na área da qualidade, como a aplicação do Controle Estatístico no processo de fabricação. Pois, na Primeira Guerra Mundial, a inspeção era realizada em todos os itens fabricados, demandava muito tempo e tornava-se um grande gargalo no processo de fabricação, além de aumentar consideravelmente os custos de produção. Com a aplicação das Cartas de Controle Estatístico, foi possível um ganho considerável de tempo nos processos de fabricação. Pois, com seu uso, era efetuada a análise de apenas um percentual dos itens fabricados, sem trazer maiores dúvidas em relação à qualidade dos demais itens naqueles lotes de fabricação [2].

Com o passar das duas grandes guerras mundiais, o mundo começou a vivenciar outra era, com uma maior complexidade e diversidade tecnológica, um considerável aumento nos investimentos em inovações e a maior cobrança da sociedade pela segurança dos produtos no mercado. Estes fatores foram essenciais para que o controle da qualidade viesse a se tornar cada vez mais crucial para a sobrevivência das empresas em meio à concorrência do mercado. Com todo este cenário, a garantia prévia de certificar a qualidade dos produtos/serviços, maquinário, e das instalações, transformou-se quase que obrigatório às empresas, o que deu origem ao Controle Total da Qualidade, formulado por Armand Feigenbaum, na segunda metade do século XX. A partir de então, iniciou-se mais uma mudança da visão da qualidade, onde a ênfase mudou da preocupação com a correção de defeitos para a prevenção e prévia detecção de erros não apenas nos produtos ou serviços, mas também nos projetos de uma forma geral, antecedendo assim as possibilidades de não conformidade dos produtos [2].

Ainda neste cenário, foram desenvolvidas muitas ferramentas e técnicas para a garantia da qualidade, que auxiliaram e deram base para os procedimentos de melhorias no mercado de produção e prestação de serviços. Muitas destas ferramentas foram criadas por engenheiros e estudiosos, e boa parte delas foram desenvolvidas e aplicadas primeiramente no Japão pós-guerra e, posteriormente, disseminadas para o mundo ocidental. Em adição, foi neste período que foi desenvolvido o modelo normativo da Internacional Organization for Standardization (ISO). Ela tem por finalidade a normatização dos produtos, processos e serviços, trazendo para as empresas, com uma certificação do selo ISO, um certo destaque das demais concorrentes do mercado [3].

A evolução dos sistemas de qualidade, e de suas ferramentas de apoio, sempre estiveram ligadas a situação em que o mercado mundial estava imerso e das necessidades e satisfação dos clientes. Passando desde as informações de qualidade boca-a-boca, até as análises e implementações criteriosas de normatização e padronização. O próximo passo dependerá das novas exigências do mercado, as quais mudam constantemente e, diversas vezes, imprevisivelmente [2].

\subsection{Qualidade nos serviços de saúde}

É notório que a visão da evolução da qualidade baseia-se mais fortemente na área da produção industrial. Fato constatado pelo elevado número de literaturas que dão destaque a esta área. Entretanto, outros setores do mercado mundial também obtiveram uma evolução da qualidade distinta em relação a seus produtos/serviços, o qual se insere, também, o mercado da prestação de serviços de atenção à saúde.

A preocupação com a qualidade nesta área teve seu início mais nítido durante a segunda metade do século XIX, na Guerra da Crimeia, com a enfermeira britânica, de naturalidade italiana, Florence Nightingale. Ela atuou em hospitais da região, trabalhando com foco na melhoria sanitária dos locais, serviços hospitalares paralelos como cozinha e lavanderia, e, evidentemente, nos cuidados de enfermagem aos pacientes feridos de guerra, que naquela época era de uma qualidade terrível. Diminuindo, desta maneira, consideravelmente a

http://dx.doi.org/10.25286/repa.v2i4.796 


\section{A Importância e o Uso de Ferramentas da Qualidade pelo Engenheiro Clínico Para o Sistema de Gestão de Acreditação Hospitalar}

mortalidade dos pacientes durante suas passagens nos hospitais, de $40 \%$ para $2 \%$ [4].

Esta foi uma enorme revolução na área de saúde, que obteve outros grandes avanços durante o século posterior, o século XX. O primeiro deles, já dando um início a uma visão mais forte e formal da qualidade na área de saúde, foi o estabelecimento do Programa de Padronização Hospitalar ( $\mathrm{PPH})$, pelo Colégio Americano de Cirurgiões (CAC), nos Estados Unidos, em meados de 1924. Neste programa, foi dada atenção a alguns pontos, como o preenchimento preciso e completo do prontuário do paciente e a organização do corpo clínico da instituição [5].

No primeiro Manual de Procedimentos, elaborado em 1924 pelo CAC, havia poucos pontos abordados. Fundamentalmente apenas à organização do corpo médico, preenchimento do prontuário do paciente (de forma abrangente), além de recursos de diagnóstico e terapêuticos, incluindo também a existência de um departamento de radiologia e outro de análises. Posteriormente, foi lançado um manual mais atualizado e mais completo e mais abrangente, contento 118 páginas, já mostrando a sua evolução e a atenção dada a esta ação. Contudo, devido ao contexto da época, final da Segunda Guerra e a crises financeiras mundiais, tornaram o CAC uma instituição insustentável. Foi neste momento, após uma parceria do CAC com outras organizações americanas e canadenses, voltadas a qualidade na prestação de serviços de saúde, que em 1952 foi criada a Joint Commission on Accredittation of Hospitals, em português: Comissão Conjunta de Acreditação em Hospitais. Uma organização não governamental, sem fins lucrativos, e com a finalidade de oferecer um selo de acreditação às OPSS voluntárias a seu processo de auditoria [5].

Acreditação é definido como um processo de avaliação certificação, realizado normalmente por órgãos não-governamentais, de caráter educativo, de participação voluntária, periódico e reservado (informações das organizações não são divulgadas), que objetiva 0 atesto da instituição com comprometimento com a qualidade em serviços de saúde. Serviço este, que pode ser oferecido não apenas a instituições privadas de saúde, como também para entidades públicas, universitárias e até filantrópicas [6].

No Brasil, a história da acreditação em serviços de saúde é um pouco mais recente. Em um convênio envolvendo a Organização Pan-Americana de Saúde (OPAS), a Federação Latino Americana de Hospitais e o Ministério da Saúde, em 1990, foi elaborado um Manual de Padrões de Acreditação para a América Latina. Já em 1995, o Ministério da saúde começava a dar os primeiros passos na elaboração do seu próprio sistema de acreditação, com investimentos no Programa Brasileiro de Acreditação. Que lançou seu primeiro Manual Brasileiro de Acreditação em 1998, a partir do manual editado pela OPAS e das experiências nos estados brasileiros [5]. Existindo várias versões atualizadas com o passar dos anos, de acordo com as experiências das instituições já acreditadas e das novas demandas que vão surgindo ao longo do tempo. Nelas, o principal objetivo é que a instituição acreditada obtenha um processo de melhoria contínua, encorajando-a sempre a querer atingir padrões mais elevados de qualidade nos serviços prestados, baseado em três níveis de abordagem: estrutura, processos e resultados [6].

Para que uma OPSS obtenha o selo de acreditação, quer ele seja nacional, pela ONA, cedido pelas Instituições Acreditadoras Credenciadas, ou internacional, por exemplo a Joint Commission International, cedido no Brasil pelo CBA, é necessário o preenchimento de alguns pré-requisitos estipulados pelos órgãos acreditadores, como a gestão dos equipamentos médico-hospitalares, o acompanhamento do desempenho dos setores, entre outros itens, e, em algumas delas, em diferentes níveis de acreditação. Isto significa que todos os processos e todos os setores, constantes nos manuais de acreditação da OPSS serão avaliados, inclusive os setores destinados ao gerenciamento dos equipamentos médico-hospitalares, normalmente designado como setor de Engenharia Clínica (EC).

\section{Engenharia Clínica}

O crescente aumento no número da diversidade e uso de equipamentos eletroeletrônicos no tratamento, diagnóstico e suporte a vida de pacientes, trouxe consigo uma necessidade natural de uma mão de obra 
especializada para que fosse possível sua manutenção quando os equipamentos apresentassem um funcionamento divergente do esperado, sua quebra em si ou no assessoramento para sua utilização. Foi assim que, em meados do fim da Segunda Guerra Mundial, deu-se início ao surgimento do serviço de Engenharia Clínica, com um curso especifico de manutenção em equipamentos médico-hospitalares, oferecido pelas forças armadas dos Estados Unidos da América [7]. Neste primeiro momento, o foco era totalmente nas manutenções de caráter corretivo, sem qualquer tipo de planejamento ou programação de manutenções ou serviços de capacitação e treinamentos para os operadores dos equipamentos. Com o desenvolvimento das tecnologias desta atividade, a multiplicidade de equipamentos, a necessidade solicitada pelo mercado, a exigência de órgãos de fiscalização e regulação, dentre outras razões, surgiu a necessidade de um aprimoramento deste serviço. Nos dias atuais, ele já está num patamar bastante avançado, onde não só são ofertadas apenas manutenções corretivas, mas uma maior diversidade de serviços nesta área, como gerenciamento total dos equipamentos médicohospitalares, gestão de equipe técnica especializada, programação de manutenções preventivas e calibrações, treinamento para utilização e cuidados com os equipamentos, análise de viabilidade referente a aquisição, manutenção e descarte dos equipamentos, gestão de documentação interna do setor, adequação aos órgãos acreditadores e agências de regulação, entre outros. Trazendo uma nova definição para este serviço, a Gestão em Equipamentos Médico-Hospitalares (GEMA) [1].

Como uma consequência do exposto, também surgiu uma nova profissão neste mercado, basicamente por uma imposição dos órgãos fiscalizadores daquela época naquele país, a do Engenheiro Clínico. Para Bronzino [1], o Engenheiro Clínico é o profissional com graduação em engenharia que aplica seus conhecimentos acadêmicos e experiências profissionais num ambiente clínicohospitalar. Ele é responsável pelo gerenciamento dos equipamentos utilizados nas OPSS, gestão da equipe técnica, relação multidisciplinar com os setores da instituição, gestão de riscos com equipamentos médico-hospitalares, dentre outras responsabilidades no ambiente clínico-hospitalar. E, para tais atribuições, deve possuir tanto conhecimentos técnicos como habilidades gerenciais, características indispensáveis para exercer a profissão, garantindo um serviço de qualidade e buscando as melhores opções com menores custos para as OPSS e maior segurança no uso dos equipamentos médicohospitalares, tanto para os pacientes como para os operadores [1].

Para instituições que desejam conquistar um selo de acreditação, seja ele nacional ou internacional, o setor de Engenharia Clínica é uma parte essencial neste processo, e o engenheiro clínico representa o responsável técnico deste setor dentro da OPSS, sendo até um item requisitado por estes órgãos acreditadores $[6,8]$, onde ele tem a missão de cooperar diretamente com outros setores e com a gestão direta da instituição, para garantir que os requisitos dos órgãos acreditadores, referentes a tecnologia médico-hospitalar, sejam alcançados.

Para o cumprimento dos pré-requisitos, constantes nos manuais de acreditação, são exigidos de vários setores das OPSS algumas determinações que são de responsabilidade da Engenharia Clínica, fortalecendo a ideia da necessidade de uma equipe multidisciplinar que trabalhe em harmonia, alcançando conjuntamente os objetivos desejados. Porém, outros requisitos são solicitados diretamente a Engenharia Clínica, sempre com foco na segurança do paciente e na procura pela melhoria contínua nos serviços de saúde. Para tais fatos, é exigido do engenheiro clínico uma relação com setores chaves da OPSS, que pode ser melhor exemplificado na Figura 1 , onde fica evidenciado o trabalho conjunto de outros profissionais (Médicos, Enfermagem, Administração da OPSS e Outros Profissionais aliados à saúde) com a Engenharia Clínica, personificada na Figura 1. como o Engenheiro Clínico, bem como a relação existente da Engenharia Clínica com órgãos externos a OPSS, como os Fornecedores (tanto de equipamentos médicos como de insumos desta área), Agências de Fomento (agências de investimento para o setor), Agências Reguladoras (como a Agência Nacional de Vigilância Sanitária (Anvisa) no Brasil), Convênios Público/Privados (convênios para o desenvolvimento de ações no setor), mostrando, desta maneira, o caráter essencial do Engenheiro Clínico nas OPSS.

O selo de acreditação nacional, oferecido pela ONA, possui três níveis diferentes de avaliação para as OPSS. São eles: [9]

http://dx.doi.org/10.25286/repa.v2i4.796 


\section{A Importância e o Uso de Ferramentas da Qualidade pelo Engenheiro Clínico Para o Sistema de Gestão de Acreditação Hospitalar}

(i) Acreditado - nível 1: caracterizado pela procura dos critérios de segurança tanto do paciente quanto dos profissionais envolvidos. Em todas as áreas, incluindo as assistenciais e as estruturais. Este nível solicita os itens básicos de qualidade no atendimento ao paciente, com estrutura compatível com a demanda da OPSS;

(ii) Acreditado Pleno - nível 2: além de atender os requisitos do nível anterior, o Acreditado, adiciona-se a busca pela gestão integrada dos setores da OPSS, com a ocorrência natural dos processos, por meio de pessoal capacitado, e da eficiência na comunicação entre as atividades, além da monitorização das atividades por meio de indicadores de desempenho;

(iii) Acreditado com Excelência - nível 3: abrangendo os níveis Acreditado e Pleno, e também compreendendo uma cultura organizacional de melhoria contínua, contemplando alguns itens específicos, como: estruturais, gestão de novas tecnologias e avanço das atividades gerenciais.

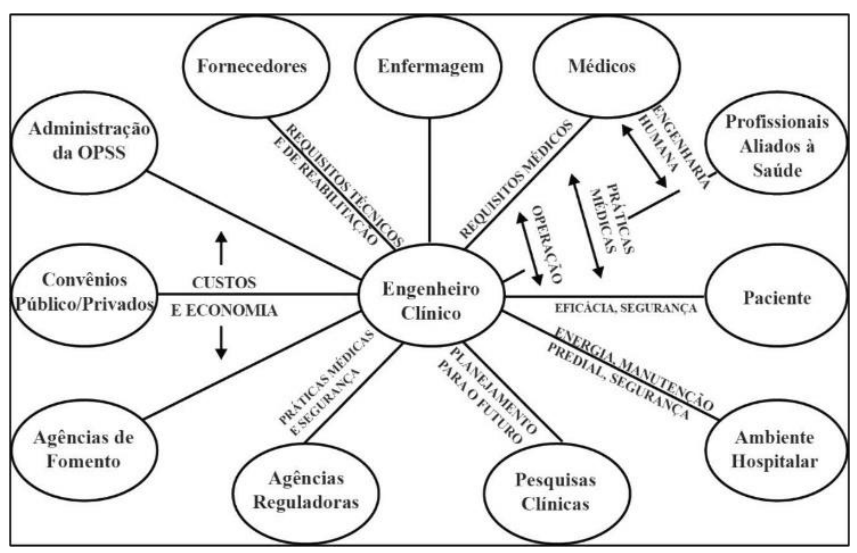

Figura 1: Relação do Engenheiro Clínico. Fonte: Adaptado de Bronzino [1].

O setor de Engenharia Clínica envolve-se com itens de orientação específicos para os níveis 1 e 2, além de outros itens constantes na competência de outros setores, porém de sua responsabilidade, como a manutenção preventiva dos equipamentos médicohospitalares dos setores da OPSS. No nível 1, acreditado, foca na operação segura do parque de equipamentos, que garante a qualidade $e$ continuidade das práticas clínicas. No nível 2, Acreditado Pleno, o foco está concentrado na melhor gestão do parque de equipamentos, verificando seus resultados e desempenho, propondo melhorias nas ações tomadas, devendo ser considerado todo o parque de equipamentos, tanto os próprios da instituição como os equipamentos médicohospitalares de terceiros, de pesquisa, cedidos por meio de contratos e convênios, além dos equipamentos de atendimento móvel (como os instalados em ambulâncias), que estão em uso na OPSS [10].

O padrão de acreditação internacional, JCI, também abrange uma linha de solicitações similar ao da ONA, referente às obrigações do setor de Engenharia Clínica. Porém, solicita, mais especificamente, um tratamento até anterior a aquisição dos equipamentos, e o controle dos seus históricos de manutenções e a preocupação com seu devido descarte após o termino da vida útil daquele equipamento para a instituição. Como também a aplicação de um programa de gerenciamento dos equipamentos, que deva contar todos os detalhes aplicados nas atividades deste setor na OPSS. [8]

Para o alcance dos requisitos solicitados pelas instituições acreditadoras, as ferramentas da qualidade oferecem uma certa segurança, praticidade e celeridade na obtenção das soluções dos problemas e adequações dos processos da OPSS, oferecendo um grande ganho de qualidade, segurança, eficiência e eficácia nos procedimentos adotados. E é com foco nestas diretrizes que serão exemplificadas e contextualizadas para o seu uso pela Engenharia Clínica num processo de aquisição ou manutenção de acreditação hospitalar.

\section{Ferramentas da Qualidade}

Para a gestão em equipamentos médicohospitalares são apresentados alguns itens de orientação nos manuais de acreditação para que sejam seguidos e preenchidos como requisitos mínimos referentes às operações com o parque de equipamentos médico-hospitalares da OPSS, durante todo o seu ciclo de vida, que pode compreende o período desde a sua pré-aquisição até o seu devido 
descarte (no fim de sua vida útil), passando pela seleção, aquisição, recebimento, teste de aceitação, capacitação, instalação, operação e a manutenção periódica do equipamento, como também o devido tratamento das queixas técnicas apresentadas pelos equipamentos durante sua utilização [8].

Para tal, o uso de ferramentas da qualidade pelo engenheiro clínico, e outras técnicas auxiliares, garantem uma melhor efetividade na obtenção de bons resultados e de um melhor aproveitamento dos recursos disponibilizados nas instituições de saúde [1].

Segundo Malik [11], ferramentas da qualidade podem ser definidas como técnicas auxiliares, ou instrumentos, que são utilizadas para mensurar, definir, analisar e propor soluções para as adversidades que ocorrem num determinado processo, em projetos, produtos ou sistemas. Sendo consideradas grandes aliadas para o alcance de um serviço, ou produto, de qualidade, que é o principal foco das instituições de acreditação hospitalar.

\subsection{Procedimento Operacional Padrão}

Para facilitação e otimização dos serviços prestados pela Engenharia Clínica numa OPSS, a elaboração de um documento descrevendo todas as atividades deste setor se torna pertinente, cabendo ao profissional com habilitação técnica ser responsável por tal. Nele, devem estar descritos os procedimentos que devam ser executados nas rotinas de um setor de Engenharia Clínica. Este documento normalmente é referenciado como Programa de Gerenciamento de Equipamentos Médico-Hospitalares (PGEMH), ou mesmo Plano de Gerenciamento de Equipamentos Médico-hospitalares, ou, até, Plano de Gerenciamento de Produtos para a Saúde, que vem a garantir a qualidade, eficácia e segurança nos serviços de saúde [12].

Este documento deve conter a descrição de ações como: atividades exercidas pela Engenharia Clínica, planejamento, seleção, aquisição, recebimento, inventário, armazenamento, transferência, instalação, intervenção técnica, descarte, avaliação e investigação de eventos adversos e ou queixas técnicas associáveis a equipamentos de saúde, dentre outras [12].

Para o preenchimento interno deste documento, como intervenção técnica, instalação e aquisição, podem ser utilizados Procedimentos Operacionais Padrão (POP), para que haja uma uniformidade de eventos rotineiros requisitados pelas organizações fiscalizadoras e órgãos de acreditação. O POP é um documento que verte o planejamento do serviço a ser executado. Nele estão contidos os passos detalhados de todas as medidas, ferramentas, acessórios e quaisquer outros itens necessários para a realização da ação pretendida. As primeiras utilizações desses POP remetem às linhas de produção de automóveis da FORD, no início do século $X X$, onde todos os automóveis eram, especificamente, da cor preta, e posteriormente foram utilizadas outras tinturas, por solicitação dos clientes, produzindo novos POP's [13].

Com o objetivo de minimizar os desvios e garantia de uma uniformidade dos processos ou produtos finais, O POP é uma ferramenta de grande utilidade para processos gerências [13]. Como exemplificação, podem ser produzidos POP's específicos para os fins de gestão de equipamentos médico-hospitalares, como testes, etapas para realização de manutenções corretivas, manutenções preventivas ou calibrações, para uso administrativo pode-se utiliza-lo para padronizar a documentação de recebimento, descarte e vistorias de equipamentos médicos, conforme solicitado pela acreditação JCI.

Alguns cuidados devem ser tomados para a elaboração e aplicação de um POP, como [13]:

- O uso de uma linguagem simples e objetiva, não utilizar cópias de outros POP's (pois não existe um padrão universal e cada um deve atender as suas necessidades específicas do seu processo ou produto);

- Deve-se conhecer bem o processo a ser documentado (para evitar desvios ou lacunas por desconhecimento de todo o processo);

http://dx.doi.org/10.25286/repa.v2i4.796 


\section{A Importância e o Uso de Ferramentas da Qualidade pelo Engenheiro Clínico Para o Sistema de Gestão de Acreditação Hospitalar}

- Deve-se treinar o executor da tarefa explicitada no POP e deve haver uma monitorização periódica da utilização do POP (para evitar os desvios por maus costumes do utilizador do POP).

Um POP que traga consigo uma segurança e qualidade deve conter alguns itens muito bem definidos, como [13]:

- Nome do procedimento: claro e direto para o entendimento da tarefa que será abordada;

- Objetivo: para qual finalidade se destina o POP;

- Documentos de referência: como manuais de equipamentos, e normas técnicas;

- Local de aplicação: ambiente onde pode-se aplicar este POP, setor da Engenharia Clínica da OPSS, por exemplo;

- Siglas: listar as siglas utilizadas no POP, caso haja. O uso de tabelas facilita sua visualização;

- Descrição sequencial das etapas do processo: especificando os executores e responsáveis de cada etapa, caso haja;

- Data da próxima revisão do POP: essencial para sua atualização periódica, e servindo também como um prazo de validade para o documento;

- Quem o elaborou: caso surjam dúvidas no decorrer do processo ou a qualquer tempo, e os operadores saibam a quem recorrer;

- Onde este documento se encontra: local que seja de fácil acesso ao executor, como por exemplo: sistema de arquivos eletrônico da empresa;
- A utilização de figuras, tabelas e fluxogramas (caso se tornem pertinentes), facilitam uma melhor visualização do processo por parte do executor.

\subsection{Fluxograma}

O uso de fluxogramas é indicado para tarefas de maior complexidade, pois torna o passo-a-passo mais visível e compreensível ao executor, ou, até, tarefas mais simples que podem ser executadas mais rapidamente e com maior segurança pelo seguimento de seus passos. Ele é composto de figuras geométricas, ligadas por setas direcionais de maneira organizada e sequencial, que podem indicar: início ou fim do processo, ação/operação, ponto de decisão, documento a ser utilizado/verificado no processo, dentre outras opções caso haja necessidade de uso. Deve-se tomar cuidado com os processos muito extensos representados por fluxogramas, pois podem estar camuflando etapas e aumentar o risco de falha ou desvio no processo. Uma maneira de reverter este fato pode ser o uso de blocos onde podem estar contidos outros fluxogramas, servindo como um modo de reduzir a informação visível para o executor [13].

Os fluxogramas podem ser inseridos dentro dos POP's, de maneira a facilitar a execução do processo por este proposto. Bastante utilizado em procedimentos como: manutenções preventivas, calibrações, verificações de funcionamento, fluxo para aquisição de novos equipamentos, dentre outros. Os fluxogramas tornam-se grandes facilitadores para a área técnica, à medida que existe uma grande variedade de equipamentos médico hospitalares e que dificilmente uma OPSS, com certa idade de funcionamento, tenha uma uniformidade de marcas e modelos destes equipamentos. Trazendo uma maior agilidade, eficácia, e descarte de retrabalho nos procedimentos executados.

\subsection{Folha de Verificação}

Para algumas atividades técnicas do setor de Engenharia Clínica, torna-se pertinente o uso de Folhas de Verificação. Folha de Verificação é definido como um formulário no qual os dados a serem coletados já estão impressos, bastando apenas o seu utilizador preencher os itens de acordo com as especificações do processo [14]. 
Ele pode ser utilizado como um documento comprobatório da realização de manutenções rotineiras, como calibrações e preventivas, e de verificações periódicas de funcionamento ou segurança elétrica de equipamentos médicohospitalares. Onde nestas intervenções os valores para análise já estarão impressos em documento próprio, bastando o técnico executar a atividade e preencher os dados e valores solicitados na Folha de Verificação. Estando esta ação elencada nos itens solicitados pelos órgãos acreditadores, de forma a dar uma maior confiabilidade e segurança no uso dos equipamentos. [1]

No qual sua estrutura deva ser personalizada de acordo com as necessidades do setor de Engenharia Clínica e da OPSS, e atendimento aos requisitos dos fabricantes dos equipamentos [1].

Em adição aos pontos de elaboração e aplicação de um POP (mostrados no subitem anterior), outro ponto devém ser adicionados para uma Folha de Verificação, como [14]:

- Campos de identificação do operador responsável pelo preenchimento do documento, assim como o seu responsável direto, geralmente o Engenheiro Clínico da OPSS;

- Campo para a identificação do responsável da OPSS onde os equipamentos médico-hospitalares estão sendo utilizados, comprovando sua ciência da ação executada;

- Data de aplicação da manutenção realizada: essencial para o seu arquivamento cronológico e programação para as manutenções seguintes.

O uso conjunto de um POP, bem elaborado, e uma Folha de Verificação, maximizam uma manutenção de qualidade e diminui substancialmente o número de possíveis erros na execução de procedimentos técnicos, já que cada passo a passo, POP, e o registro das atividades de interesse, Folha de Verificação, estarão disponíveis ao operador.

\subsection{Indicadores}

Outro item que é um requisito de verificação pelos órgãos acreditadores, ONA nível 2 e JCI, e mesmo que não fosse exigido é uma ferramenta de grande utilidade e que deve ser sempre monitorado e procurado, é a melhoria contínua dos processos executados e dos índices alcançados periodicamente pela Engenharia Clínica.

Um conceito bastante utilizado para a busca da melhoria contínua vem do Japão, pós Segunda Guerra Mundial, o Kaizen. Este conceito utilizado, que teve como principal idealizador Masaaki Imai, conhecido como "O pai da estratégia Kaizen", para a reestruturação industrial daquele país naquela época. Ele é baseado nos costumes e filosofias japonesas, o Kaizen, que deriva do Kai (mudança) e de Zen (bom), tem em sua natureza uma concepção de uma busca contínua pelo melhoramento dos processos e dos resultados [15].

Este conceito pode ser explorado na busca e difusão pelas melhorias conquistadas e descobertas, dia após dia, nos processos executados pelos colaboradores, como a redução do tempo gasto, o aumento da qualidade dos serviços executados e a economia financeira conquistada. Todos os pontos que forem identificados e verificados como uma melhoria devem ser divulgados para toda a equipe de trabalho, buscando sempre a uniformização dos processos [15].

Porém, muitas vezes este recurso necessita de alguma base, alguma referência para ser aplicado. Para esta atividade, devem ser aplicados e utilizados, no setor de Engenharia Clínica, os indicadores de desempenho de qualidade, também conhecidos por Quality Performance Indicador (QPI) [1].

Indicadores de desempenho são ferramentas de monitoramento que tem a função de verificar a eficiência e a eficácia das atividades dos setores ou de uma empresa em geral. O uso de indicadores é de extrema necessidade para a verificação e

http: / /dx.doi.org/10.25286/repa.v2i4.796 


\section{A Importância e o Uso de Ferramentas da Qualidade pelo Engenheiro Clínico Para o Sistema de Gestão de Acreditação Hospitalar}

melhoramento dos serviços de qualquer setor ou empresa. Ele traz consigo dados que podem evidenciar em que ponto o setor possa estar se deparando com alguma deficiência ou dificuldade, acelerando a implementação de algum plano de correção ou simplesmente o seu acompanhamento, caso as metas dos indicadores tenham sido atingidas. Aplicando, assim, uma cultura de melhoria contínua em toda a equipe [16].

A escolha dos indicadores deve ser aplicada e adaptada à realidade do setor de Engenharia Clínica em cada OPSS, pois cada um possui sua particularidade, e podem ser adicionados e, ou, excluídos a qualquer tempo dependendo da necessidade do setor, sendo devidamente justificadas. Estes indicadores devem ser claros, objetivos e devem possuir uma certa relevância para o setor e a OPSS, assim como uma meta, préestabelecida, a ser atingida periodicamente por cada indicador, de preferência mensalmente, tornando-o mais visível a toda a equipe e mais fácil de ser comparado e gerenciado [1].

$\mathrm{Na}$ visão de Bronzino [1], para a escolha dos indicadores a serem utilizados, podem ser seguidos os seguintes passos:

- Verificar qual variável deve ser acompanhada;

- Estabelecer quais os dados que devam ser capturados para esta variável;

- Realizar a coleta desses dados;

- Definição de metas alcançáveis para estas variáveis;

- Realizar o gerenciamento das informações que esses indicadores podem trazer.

Como exemplos de indicadores de desempenho que podem ser utilizados pela Engenharia Clínica, podem ser citados:
- Tempo de atendimento a chamados de manutenção corretiva;

- Quantidade e percentual de manutenções planejadas realizadas, incluindo manutenções preventivas, calibrações e testes de verificação periódicos;

- Quantidade e percentual de manutenções corretivas concluídas;

- Tempo médio de parada dos equipamentos enquanto em manutenção;

- Custos totais gerados pelas manutenções, como compra de peças para conserto de equipamentos, e ações da Engenharia Clínica, como treinamentos para utilização de equipamentos mais complexos;

\subsection{Diagrama de Ishikawa}

A partir da análise dos resultados dos indicadores, individualmente e coletivamente, pode-se verificar onde devém ser direcionados os esforços por parte da equipe para que se busque a melhora e cumprimento das metas pré-estabelecidas, garantindo o alcance do beneficiamento dos processos.

Para esta análise, e uma futura tomada de decisões em relação aos problemas que possam estar impedindo o cumprimento das metas, outra ferramenta bastante útil é o Diagrama de Causa e Efeito, também conhecido como Diagrama Espinha de Peixe (dado o seu formado gráfico de "esqueleto" de peixe), ou Diagrama de Ishikawa, tomando o nome de seu desenvolvedor, Kaorou Ishikawa [17].

Este diagrama permite identificar e explorar, graficamente, as possíveis causas de um problema específico ou fatores que venham a interferir no processo, como a baixa eficácia nas manutenções corretivas ou o não seguimento de qualquer fluxo de trabalho. Estas causas devem ser analisadas com toda a equipe envolvida, tanto a interna quanto a de outros 
setores interessados na solução do problema, pois podem ser evidenciados os motivos que o Engenheiro Clínico possa não estar reconhecendo, fortificando ainda mais o envolvimento multidisciplinar da OPSS, e, além do exposto, sendo uma evidência para as instituições acreditadoras do alto nível de gestão em aplicação, requisito cobrado para a ONA nível 2 [10].

As possíveis causas do problema podem ser levantadas por meio de algumas técnicas, dentre elas o brainstorming. Nesta etapa são levantadas todos e quaisquer fatos que possam estar ocasionado o problema em si, desde as ideias mais inesperadas as mais complexas possíveis, dinamizando o alcance $\mathrm{da}(\mathrm{s})$ causa(s) raiz(es) do problema [17].

As causas podem ser divididas em seis categorias, segundo este diagrama, conhecidos como os 6 M's. São eles [17]:

- Método: é o método de execução dos serviços especificados, é a maneira de como eles são aplicados;

- Matéria-prima: item relacionado com a matéria-prima utilizada na execução dos serviços, como peças de reposição ou itens descartáveis;

- Mão de obra: problemas relacionados a mão de obra utilizada, como falta de capacitação, pressão na execução dos serviços, imprudência, dentre outros;

- Máquinas: está vinculado com os equipamentos e ferramentas utilizados para as manutenções, que podem estar com defeitos, desgastadas ou serem inadequados para aquela operação;

- Medida: envolve os instrumentos de medida, calibração, acompanhamento de indicadores e sua efetividade;

- Meio Ambiente: o ambiente em si, que pode oferecer variáveis fora do desejado, como poluição, temperatura e humidade fora dos padrões 93 recomendados, espaço mal dimensionado, dentre outros.

Graficamente, estas causas irão compor, cada uma, uma costela de um peixe, enquanto o efeito (o problema que estaria sendo sondado sua solução) seria a coluna vertebral de um peixe. Resultando, assim, a imagem de uma espinha de peixe ao diagrama, exemplificado na Figura 2

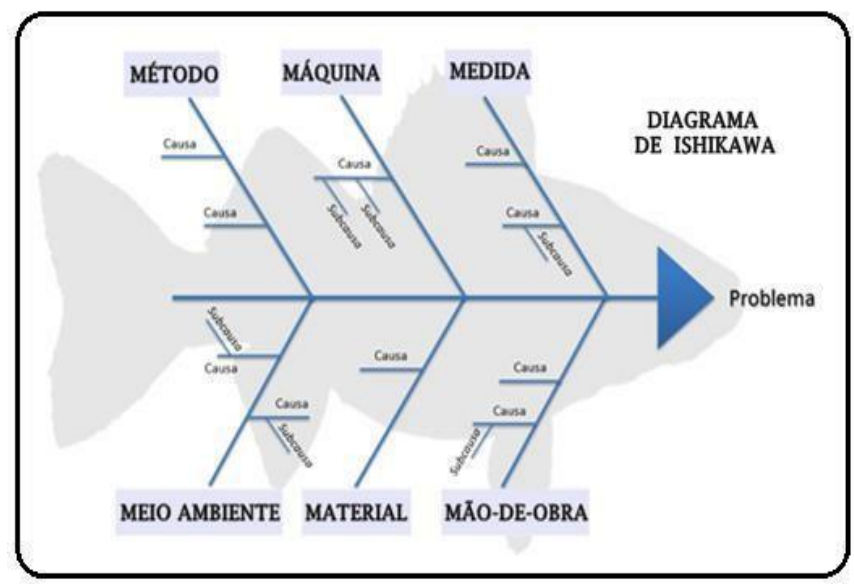

Figura 2: Diagrama de Ishikawa. Fonte: Adaptado de http://www.portal-administra-cao.com/2014/08/diagramade-ishikawa-causa-e-efeito.html.

Após a montagem das causas em suas categorias e, focando no problema especificado por elas, a visualização da sua causa raiz fica melhor evidenciado graficamente. Assim podem ser tomadas as melhores medidas para a solução deste [17].

Porém, é uma ferramenta que demanda bastante trabalho, pois a cada novo problema, deve-se percorrer todas as etapas de levantamento de possíveis causas, diagramação e visualização do problema. Havendo a necessidade de novas reuniões por parte dos interessados, tornando o trabalho repetitivo e cansativo. Deve ser utilizado para problemas que afetem com certa gravidade a organização ou o gerenciamento do parque de equipamentos médico-hospitalares desta, ou ainda, que esteja abrangendo vários setores críticos e que necessitam de uma solução eficaz a todos.

http://dx.doi.org/10.25286/repa.v2i4.796 


\section{A Importância e o Uso de Ferramentas da Qualidade pelo Engenheiro Clínico Para o Sistema de Gestão de Acreditação Hospitalar}

\subsection{Ciclo PDCA}

Uma ferramenta, que também é difundida como conceito, que não deve ser descartada para um bom gerenciamento dos equipamentos médicohospitalares de uma OPSS é o Ciclo PDCA. O ciclo PDCA foi inicialmente idealizado pelo americano Walter A. Shewhart, através do

Ciclo de Shewhart, e disseminado, pelo estatístico, também americano, William E. Deming durante a metade do século $X X$. Como algumas outras ferramentas e técnicas da qualidade, ela é advinda do Japão pós Segunda Guerra Mundial, evidenciando a grande participação deste país para a história e evolução da gestão da qualidade [3].

A indicação de seu uso, primordial para a manutenção do título de organização acreditada à OPSS, vem da solicitação dos órgãos acreditadores, que analisam a melhoria contínua dos processos já acreditados anteriormente. As letras da sigla PDCA, termo em inglês, definem sua funcionalidade. Sendo [18]:

- Plan (planejar): é uma das etapas mais importantes do ciclo, pois se trata do primeiro ponto de partida, a do planejamento das ações. Nesta fase é onde ocorre o levantamento dos dados, análise desses dados e o estabelecimento dos objetivos;

- do (executar): aqui é posto em pratica as ações e estabelecidas na fase anterior (Plan), após devida qualificação, através de treinamento e orientações, a todos os executores das ações previstas, devendo haver uma aplicação gradual e coordenada das ações, sempre objetivando as metas que foram estabelecidas;

- Check (verificar): esta fase tem por objetivo verificar as ações planejadas e executadas até então, segundo as diretrizes tomadas. Sendo os resultados coerentes com o que poderia ser esperado na fase de planejamento;
- Action (ação): esta etapa pode ser configurada em duas vertentes, a primeira é, caso os resultados obtidos estejam em conformidade com os esperados, mostrando assim a eficácia das ações tomadas. Neste caso positivo, deve-se tornar a ação uma rotina, um padrão, sempre esperando seus melhores resultados. Em segunda alternativa, caso os resultados estão desconformes com o esperado, deve-se verificar e aplicar as correções necessárias ou, em casos mais graves, pode-se aplicar novos planos de ação, sempre visando as metas pretendidas.

Estes quatro pontos formam o Ciclo PDCA, mostrado na Figura 2, que deve ser rodado continuamente, para que sejam mantidos os padrões de eficácia, eficiência e efetividade desta ferramenta [18].

Com o auxílio desta ferramenta, pode-se gerenciar toda a operação das manutenções preventivas, verificações de funcionalidade periódicas, testes de verificação de segurança elétrica e calibrações (Do), que normalmente tem planejamento anual (Plan) e verificação de sua efetividade mensal (Check). Havendo qualquer discordância, entre as manutenções planejadas e os indicadores que as mapeiam, que são de suma importância, deve-se executar um plano secundário de ação (Action), buscando, desta maneira, o cumprimento das metas pré-estabelecidas para tal atividade.

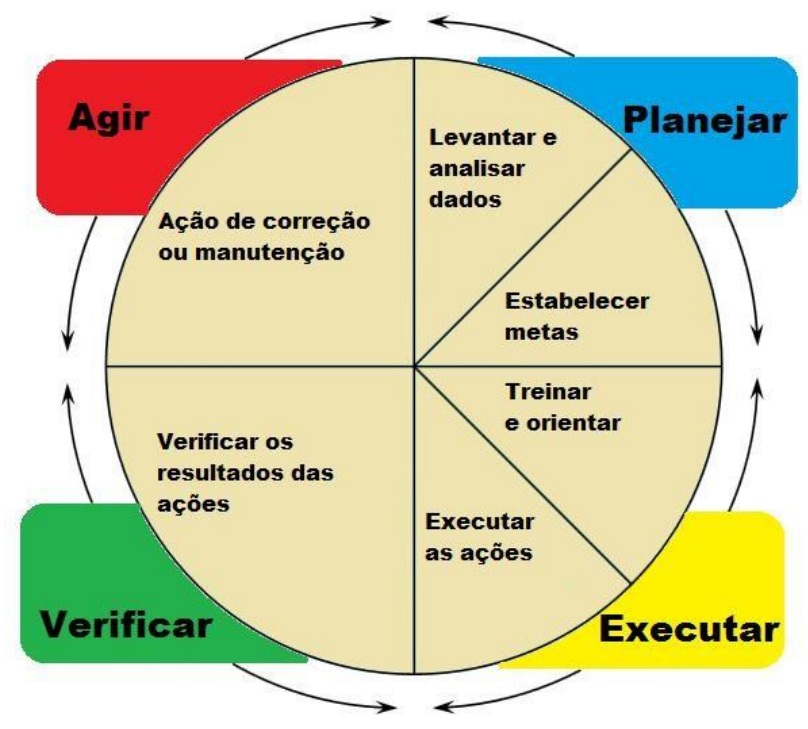

Figura 3: Ciclo PDCA. Fonte: Adaptado de Camargo [18]. 


\section{Conclusões}

A obtenção e manutenção do selo de acreditação hospitalar traz à OPSS:

- Envolvimento do Setor de Engenharia Clínica no processo de Acreditação Hospitalar;

- Uma diretriz em busca da melhoria contínua na assistência aos pacientes, sempre na procura da superação da expectativa de atendimento destes;

- Um ambiente de trabalho controlado com níveis cada vez maiores de qualidade, eficiência, eficácia e segurança;

- Uma maior competitividade empresarial no mercado de assistência à saúde.

Destarte, este artigo apresentou como se deu a evolução da qualidade e como ela foi situada na área da saúde e cuidados com o paciente, chegando até o momento da demonstração da importância do profissional de engenharia clínica para uma OPSS na atualidade. Além de contribuir, para os Engenheiros Clínicos, como material de consulta e orientação na aplicabilidade de Ferramentas Gerenciais da Qualidade, atendendo os padrões requisitados pelas acreditações hospitalares ONA e JCI, no que se refere ao gerenciamento de equipamentos médicohospitalares.

\section{Referências}

[1] Bronzino, Joseph D. Clinical Engineering. CRC Press, 2003.

[2] Fernandes, Waldir Algarte. O movimento da Qua-lidade no Brasil. Essential Idea Publishing. 2011.

[3] Carvalho, Marly Monteiro de; Paladini, Edson Pacheco. et. al. Gestão da qualidade: teoria e caos. 8. ed. Rio de Janeiro: Elsevier. 2005.

[4] PAIXÃO, Waleska. História da Enfermagem. Rio de Janeiro: Júlio C. Reis. 1979.

[5] Feldman, L. B.;Gatto, M. A. F.; Cunha, I. C. K. O. História da evolução da qualidade hospitalar: dos pa-drões à acreditação. Acta
Paulista de Enfermagem, v. 18, n. 2, São Paulo, 2005.

[6] Organização Nacional de Acreditação (ONA). Manual para Avaliação e Certificação de Organi-zações Prestadoras de Serviços Hospitalares. Brasília, 2014.

[7] Ramirez, E. F. F.; Calil, S. J. Engenharia Clínica: Parte I - Origens (1942-1996). Semina: CI Exa-tas/Tecnol. Londrina, v.21, no4, p. 27-33, dez. 2000.

[8] Joint Commission International (JCI). Joint Com-mission International Accreditation Standarts for Hospitals 5th Edition. http://www.jointcommissioninternational.org/jci-hospital-5th-editionebook-package-english-/, março de 2014.

[9] Organização Nacional de Acreditação (ONA).

Caderno Institucional. https://www.ona.org.br/Pagina/20/A-ONA.

[10] Organização Nacional de Acreditação. MA5/2: Gestão de Equipamentos e Tecnologia Médico-Hospitalar. Brasilía, 2006.

[11] Malik, A. M.; Schiesari, L. M. C. Qualidade na gestão local de serviços e ações de saúde. São Paulo: FSP-USP, 1998.

[12] BRASIL. Anvisa. Consulta Pública n070 de 11 de julho de 2007. Brasília: Anvisa, 2007.

[13] Scartezini, Luís Maurício Bessa. Análise e Me-Ihoria dos Processos. Goiânia, 2009.

[14] Werkema, M.C.C. Ferramentas Estatísticas Bási-cas para o Gerenciamento de Processos. Belo Horizonte: Werkema Editora LTDA, 2006.

[15] Briales, Júlio Aragon. Melhoria contínua através do kaizen: Estudo de caso Daimler Chrysler do Brasil. Dissertação de Mestrado em Sistema de Gestão. Universidade Federal Fluminense, Nite-rói - RJ, 2005.

http: / /dx.doi.org/10.25286/repa.v2i4.796 
[16] Pegoraro, Alysson Hoffmann. Uma Metodologia para a Avaliação e Melhoria da Qualidade em Empresas de Serviços com o Uso de Indicadores. Florianópolis. Dissertação de Mestrado em En-genharia de Produção - Centro Tecnológico, Universidade Federal de Santa Catarina, 1999.

[17] Araújo, Luís César G. de. Organização, Sistemas e Métodos e as tecnologias de Gestão Organiza-cional. $2^{a}$ edição. São Paulo: Atlas, 2006.

[18] Camargo, Wellington. Controle de Qualidade To-tal. Instituto Federal do Paraná, Ministério da Educação, Paraná, 2011. 